\title{
Centros Municipais de Educação Infantil Financiado pelo Proinfância e as Possibilidades do Desenvolvimento de Práticas Educativas Sustentáveis
}

\author{
Municipal Early Childhood Education Centers Financed by Prochildhood and \\ Possibilities for The Development of Sustainable Educational Practice
}

\section{Graciele Cristiane Rambo $^{1}$ e Terezinha Corrêa Lindino ${ }^{2}$}

1. Pedagoga. Pós-graduanda em Gestão, Supervisão e Orientação Escolar e Educação Especial. Mestranda do Programa de Ciências Ambientais pela Universidade Estadual do Oeste do Paraná (UNIOESTE/Campus de Toledo). Professora da Secretaria Estadual de Educação do Paraná (SEED). Diretora na rede municipal de ensino de Marechal Cândido Rondon, PR. ORCID: https://orcid.org/0000-0002-8760-8961

2. Pós-doutorado em Gestão e Educação Ambiental, realizado na Universidade Estadual Paulista Júlio de Mesquita Filho (UNESP/Campus Tupã), no Grupo de Pesquisa em Gestão e Educação Ambiental (PGEA). Doutora em Educação pela Universidade Estadual Paulista Júlio de Mesquita Filho (UNESP/Campus Marília). Professora Associada B na UNIOESTE/Campus Marechal Cândido Rondon). Docente permanente no Programa de Pós-Graduação Stricto Senso em Ciências Ambientais (UNIOESTE/Campus Toledo). Vice-líder do Grupo de Estudo e Pesquisa em Ciências Ambientais (GEPECIA). Vice-líder do Grupo de Estudo e Pesquisas sobre a Primeira Infância (GEPEPI). Membro do Grupo de Pesquisa em Gestão e Educação Ambiental (PGEA). ORCID: https://orcid.org/0000-0001-5290-7702

graciele.rambo@hotmail.com e terezinhalindino@gmail.com

\section{Palavras-chave}

Brincadeiras Educativas

Centro de Educação Infantil

Realidade da Educação

\section{Keywords}

Childhood Education Center

Educational Games Early

Education Reality

Artigo recebido em: 20.08.2021.

Aprovado para publicação em: 22.09.2021.

\begin{abstract}
Resumo:
Nas últimas décadas a humanidade tem estabelecido uma relação de descompasso com o meio ambiente, situação a qual em termos de futuro do planeta Terra tem requerido cada vez mais a construção de ambientes que possibilitam a formação dos indivíduos que sejam capazes de entender a sua parcela de atuação para preservação e cuidado com os recursos naturais. Entende-se que nesse contexto ofertar desse tipo de experiência na Primeira Infância possibilita aproximar a criança da vivencia com a natureza e a construção de seus próprios conceitos sobre a vida e os elementos naturais que a compõem. Sendo assim, o objetivo desse artigo visa trazer um pequeno ensaio que possibilita a reflexão sobre a teoria e prática dentro da proposta de trabalho com o público infantil visando compreender como os espaços formais de ensino e sua arquitetura ofertada a partir do Programa Proinfância possibilita o desenvolvimento de práticas educativas sustentáveis. Para tanto, utilizou-se como método de estudo a revisão literária sobre a institucionalização dos espaços destinados a educação infantil, como também, a análise iconográfica para exemplificações dos aspectos discutidos. Conclui-se que os Centros Municipais de Educação Infantil quando pensados e planejados no intuído de possibilitar vivências com o mundo natural pode tornar-se um 'laboratório' de descobertas, familiarizando os pequenos ao contato com todas as formas de vida por meio da curiosidade avivada com as brincadeiras. Possibilitando assim trabalhar aspectos como: ética, a sensibilidade, cuidado e o despertar do pertencimento da criança ao mundo natural.
\end{abstract}


tion of their own concepts about life and the natural elements that compose it. Thus, the objective of this article aims to bring a small essay that enables reflection on theory and practice within the proposal of working with children to understand how the formal teaching spaces and their architecture offered by the Pro Childhood Program enable the development of sustainable educational practices. For this purpose, the literary review on the institutionalization of spaces for early childhood education was used as a study method, as well as the iconographic analysis to illustrate the discussed aspects. It is concluded that the Municipal Child Education Centers, when thought and planned to enable experiences with the natural world, can become a 'laboratory' of discoveries, familiarizing the little ones with contact with all forms of life through quickened curiosity with the games. This makes it possible to work on aspects such as: ethics, sensitivity, care, and the awakening of the child's belonging to the natural world.

\section{INTRODUÇÃO}

A relação de distanciamento que o ser humano tem estabelecido com a natureza, nas últimas décadas, tem refletido de uma forma muito negativa e trazendo como resultado o desgaste dos recursos naturais e a falta de cuidado e empatia com o meio ambiente. Não é finalidade, desse ensaio, adotar uma postura determinista e romantizada quanto à relação do ser humano e a natureza, nem tão pouco buscar estratégias que visem a esse convencimento; pois, seria ingênuo acreditar que apenas o fato de ter a natureza próxima de si seja o suficiente para que os indivíduos mudem sua postura com relação ao cuidado e preservação.

Por outro lado, o extremo oposto também parece inadequado, ao pensar que uma criança que seja criada até idade adulta em um ambiente totalmente distante do contato com a natureza, privada de qualquer tipo de experiência com o meio ambiente, poderá em sua formação adulta compreender a importância dos recursos naturais para todas as formas de vida do planeta, inclusive a dela.

As principais razões que justificam a relevância desse estudo se baseiam no contexto histórico oportuno quanto à reflexão e a ação em prol da criança, considerando que a Primeira Infância, cada vez mais pauta de discussão tendo em vista os estudos e pesquisas, o qual tem possibilitado a compreensão da importância des sa fase da vida para o desenvolvimento humano e, por seguinte, o campo das discussões ambientais.

A humanidade se encontra em uma situação cada vez maior de degradação do meio ambiente e assim urge a necessidade da formação de uma geração que seja capaz de entender seu lugar no mundo a sua parcela de atuação para a preservação e o cuidado com os recursos naturais. Assim sendo, o que se busca é traçar uma linha de raciocínio que visa ao final dessa discussão demonstrar que ter uma infância saudável que pos sibilite brincar, explorar, conhecer e interagir com os mais variados aspectos que envolvem a biodiversidade do nosso Planeta, se constitui uma das inúmeras peças desse imenso mosaico que busca formar o cidadão para a posterioridade, o qual possa contribuir para a construção de um futuro mais sustentável.

A escola como espaço formal de ensino tende a contribuir para que aspectos relevantes quanto a formação desse cidadão sejam concretizadas. Neste sentido, acredita-se que a arquitetura destinada a essa instituição torna-se um espaço capaz de ampliar, ou até mesmo limitar, o desenvolvimento de práticas educativas sustentáveis, dentro do cenário pedagógico.

Nota-se que a principal finalidade das discussões levantadas se finda em refletir sobre a estrutura física dos Centros Municipais de Educação Infantil construídos pelo ProInfância (Programa do Governo Federal), suas possibilidades para o desenvolvimento de práticas educativas sustentáveis e analisar os espaços destina dos a educação infantil. Ao entender como estes são projetados e pensados, nos permite observar como essas práticas educativas podem ser desenvolvidas e o quanto se tornam significativas para a formação cidadã da criança que este espaço frequenta. 
Desta forma, adotou-se a revisão de literatura sobre a institucionalização dos espaços destinados à educação infantil como metodologia neste ensaio, cuja análise do escopo selecionado possibilitou com que fossem traçados os tópicos que o compõem; bem como, a análise iconográfica tende a enriquecer as discussões por meio de exemplificações.

\section{Estruturas de CENTROS MUNiCIPAIS}

Para melhor compreensão do tema trabalhado em um primeiro momento será apresentado à evolução do significado de infância e o espaço atribuído a ela dentro do contexto histórico de formação da sociedade bra sileira do qual resultou em um olhar para esse sujeito enquanto um ser de direitos e como consequência a institucionalização de espaços escolares encarregados para seu atendimento.

Por conseguinte a apresentação do Proinfância enquanto política pública que visa garantir a qualidade, equidade e o acesso da criança em creche e pré-escolas nos municípios e distrito federal, e como essa pode possibilitar ou não a interação da criança com a natureza.

\section{INSTITUIÇÕES PRÉ-ESCOLARES NO BRASIL}

O espaço da criança e o significado de infância foram marcados por diferentes momentos da história de formação da nação na sociedade brasileira. Essas transformações influenciaram o processo de sua construção como sujeito de direitos na legislação brasileira, ao mesmo tempo em que alavancou as discussões acerca da importância dessa fase da vida dentro do processo de desenvolvimento motor, social e cognitivo do ser humano.

Por esse motivo, para que se possa entender como se estruturou e consolidou os espaços institucionais encarregados do atendimento às crianças pequenas, de acordo com sua configuração atual, torna-se significativo pontuar os principais aspectos que marcaram sua história e trajetória com base em sua estreita relação com as questões que dizem respeito, a família, aumento da população, a urbanização, o trabalho e as relações de produção (KUHLMANN Jr., 2011).

Sabe-se que, mundialmente, até meados da Idade Média o alto índice de mortalidade infantil revela um silêncio histórico e anonimato quanto aos registros sobre sua existência, as crianças pobres conformem cresciam “[...] eram inseridas no mundo do trabalho, sem qualquer diferenciação entre adultos e crianças. As cri anças nobres tinham seus educadores e eram vistas como miniaturas dos adultos” (ANDRADE, 2010, p. 49), devendo ser educada e preparada para a transição da vida adulta.

O século XVIII faz emergir um novo sentimento de infância, colocando-a em uma condição oposta a do adulto. Nesse contexto, a separação entre o púbico e o privado colocou para a família assumir novas obrigações quanto ao cuidado com seus pequenos, “[...] as mudanças no interior das famílias e a necessidade de educação das crianças são fatores determinantes para o desenvolvimento do sentimento de infância” (AN DRADE, 2010, p. 51).

Dentro dos estudos sobre a criança e a infância evidencia-se que o advento da modernidade traz seu re conhecimento social, “[...] ou seja, é com o projeto de modernidade que a infância sai do anonimato, tor nando-se objeto de estudo de várias áreas do saber” (Idem, p. 56).

No Brasil, a história das instituições destinadas à infância por um longo período tiveram suas raízes voltadas para um caráter muito mais assistencialista do que educacional, como se pode evidenciar durante o pe- 
ríodo Colonial, quando cria-se a Santa Casa de Misericórdia, em Salvador logo após no Rio de Janeiro, “[...] nesse espaço atendia-se a bebês abandonados pelas mães solteiras que buscavam esconder a desonra de espe rar um filho ilegítimo, ou famílias de condições precárias”, também conhecido como Roda dos Expostos (MENDES, 2015, p. 96).

Os primeiros indícios demonstram que um olhar diferenciado para a criança surge em 1823, quando durante debates realizados na Assembleia Constituinte, no Rio de Janeiro, discutia-se a necessidade de uma educação para a mocidade, “[...] inicialmente, a preocupação com as crianças estava diretamente relacionada aos debates sobre a própria formação do povo e do cidadão brasileiro” (ROMAN; STEYER, 2001, p. 30). No entanto, somente após a Proclamação da República que se passa a criar algumas iniciativas destinadas a proteção da infância, considerando que a abolição da escravatura e consequentemente de seus filhos, assim como o grande êxodo rural em busca de melhores condições de vida na cidade com o advento da industriali zação trouxeram alguns problemas sociais de abandono da infância, requerendo proteção e cuidado .

Assim durante esse período “[...] são criadas entidades de amparo à criança, ou seja, as creches, asilos e internatos, objetivando o combate ao alto índice de mortalidade infantil e assegurar o cuidado das crianças pobres” (MENDES, 2015, p. 97).

A primeira iniciativa de criação de pré-escolas no Brasil se deu por volta de 1889, quando fundado a primeira Instituição de Proteção e Assistência à Infância, localizado no Rio de Janeiro:

Ela foi pioneira na pré-escola brasileira. Neste mesmo ano, foi inaugurada a creche da Companhia de Fiação e Tecidos Corcovado (RJ), criada para acolher os filhos de operários. Os primeiros espaços destinados para o cuidado das crianças pequenas foram criados com uma visão de prestação de serviços (MENDES, 2015, p. 98).

No entanto, na metade do século XIX, as teorias de Froebel ganham espaço mundialmente, pois considerava que as crianças pequenas deveriam ser cuidadas com carinho e ser os agentes de seu próprio desenvolvimento, este foi “[...] considerado o criador dos jardins-de-infância (Kindergarten)” (DROUET, 1995, p. 13), a qual a princípio deu o nome de “[...] viveiros infantis” (Ibidem).

E, inspirados nas ideias de Froebel, criam-se no Brasil os primeiros jardins de infância particulares, primeiramente no Rio de Janeiro, em 1875 no Colégio Menezes Vieira, dois anos depois em São Paulo, na Es cola Americana, “[...] posteriormente, foram fundados os jardins-de-infância público destinado para a elite social brasileira, os quais possuíam um programa pedagógico para o desenvolvimento educativo das crianças” (MENDES, 2015, p. 98).

Reforçando as bases de uma visão dualista de educação infantil, marcando de um lado a oferta de uma educação para o desenvolvimento da aprendizagem aos herdeiros da alta sociedade e de outro uma educação assistencialista pautada no cuidar destinada aos menos favorecidos. Segundo Kuhlmann Jr. (2011), três segmentos da sociedade teriam influenciado a criação de instituições pré-escolares, creches, escolas maternais e jardins de infância no Brasil, entre eles: os médicos/higienistas, os juristas e a religião.

As descobertas no campo científico da epidemiologia por volta de 1870, possibilitou o avanço no combate a mortalidade infantil, com isso os médicos ganharam espaço nas discussões sobre a criança, trazendo também a proposta de saneamento básico como forma de atingir a civilidade e a modernidade. O médico pediatra passa a divulgar normas racionais de cuidado com a infância "[...] condenando práticas como a de contratação de amas de leite, e do sistema Roda de Expostos” (ROMAN; STEYER, 2001, p. 22), orientando sobre a postura que deveria ter as mães de família tanto pobres como ricas valorizando o papel da mulher como guardiã do lar. 
A creche nesse projeto higienistas seria elemento crucial e eficaz no cuidado e no controle epidemiológico e liberação da mão de obra feminina para as fábricas e serviços domésticos. A influência jurídica se desta ca no campo da pobreza, vista como uma ameaça a tranquilidade da elite, acarreta a criação de “[...] normas para o novo tipo de atendimento a infância, a fim de evitar a criminalidade” (KUHLMANN Jr., 2011, p. 93), estabelecendo assim os objetivos do Patronato de Menores, que dentre outras funções previa a fundação de “[...] creches e jardins de infância; proporcionar aos menores pobres recursos para o aproveitamento do ensi no público; incutir no espírito das famílias pobres os preciosos resultados da instrução” (Ibidem).

A contribuição religiosa teve suas raízes fundadas na Igreja Católica, vista na época, como a única instituição capaz de trazer a salvação e a ordem social ao povo. Sua contribuição esteve presente na implementação das novas políticas assistenciais como forma de controle da classe trabalhadora.

Por longas décadas a instrução voltada para as crianças pobres esteve fortemente vinculada a saúde com o apoio de entidades filantrópicas, pautando-se dentro de uma perspectiva que se preocupou muito mais com a higiene e o cuidado físico do que com a educação para o desenvolvimento cognitivo dos pequenos. Em nosso país pode se dizer que a educação infantil passa apresentar pequena ascensão após a segunda metade do século XIX, com o avanço científico sobre o desenvolvimento infantil, inserção cada vez maior da mulher no mercado de trabalho gerando pressões na sociedade o qual passa a "[...] exigência de creches como um di reito do trabalhador e dever do Estado” possibilitando o reconhecimento da criança como sujeito de direitos, especialmente em seus primeiros anos de vida (MENDES, 2015, p. 107).

Nesse contexto a Constituição Federal de 1988, significou um marco na trajetória dos direitos da criança brasileira ao lhe reconhecer enquanto sujeito de direitos responsabilizando tanto a família como o próprio Estado para que seus direitos, sejam assegurados. Coube ao Estado a responsabilidade e a garantia da “[...] educação infantil, em creche e pré-escola, às crianças até 5 (cinco) anos de idade” (BRASIL, 1988).

Pode se dizer que a educação infantil recebeu atenção especifica somente após a aprovação da Lei de Diretrizes e Bases da Educação Nacional, (LDB) em 1996, quando está então passa a ser tratada como primeira etapa da educação básica tendo “[...] como finalidade o desenvolvimento integral da criança de até 5 (cinco) anos, em seus aspectos físico, psicológico, intelectual e social”, devendo ser oferecidas em “[...] c reches, ou entidades equivalentes, para crianças de até três anos de idade” e em "pré-escolas, para as crianças de 4 (quatro) a 5 (cinco) anos de idade” (BRASIL, 1996).

A partir de então lançam-se as bases dos debates e discussões quanto a efetivação de politicas públicas objetivando não só a garantia de acesso a primeira etapa da educação básica como a qualidade do serviço prestado, o ProInfância dentro dessa dinâmica pode ser estudado como uma das políticas implantadas para esse fim.

\section{Politicas Públicas Para a Educação Infantil - Proinfância}

O ProInfância caracteriza-se como um Programa Nacional, formulado pelo Ministério da Educação (MEC) e mantido pelo Governo Federal. Tem como finalidade prestar assistência financeira para Reestruturação e Aquisição de Equipamentos para a Rede Escolar Pública de Educação Infantil, dos municípios e Distrito Federal.

Instituído em 2007, pelo então atual Ministro da Educação Fernando Haddad, o programa fez parte do Plano de Desenvolvimento da Educação (PDE) juntamente com o Ministério da Educação (MEC), que por meio do Decreto $\mathrm{n}^{0}$ 6.094, de 24 de abril de 2007 implementou o Plano de Metas Compromisso Todos pela 
Educação, o qual buscou o compromisso entre “[...] União, Estados, Distrito Federal e Municípios, atuando em regime de colaboração, das famílias e da comunidade, em proveito da melhoria da qualidade da educação básica” (BRASIL, 2007).

Assim, o ProInfância regido pela Resolução nº 6, de 24 de abril de 2007 buscou “[...] garantir o acesso de crianças a creches e pré-escolas, bem como a melhoria da infraestrutura física da rede de educação infantil em todo Brasil” (FALCIANO; NUNES; SANTOS, 2019, p. 257). O foco do programa busca pleitear a promoção de "ações supletivas e redistributivas, para correção progressiva das disparidades de acesso e de garantia do padrão mínimo de qualidade de ensino” para o público infantil (BRASIL, 2007).

Nesse sentido, conforme aponta Falciano, Nunes e Santos (2019), o programa atua sobre dois eixos principais: construção de creches e pré-escolas, utilizando projetos padronizados fornecidos pelo Fundo Nacional de Desenvolvimento da Educação (FNDE), ou próprios elaborados pelos proponentes, os quais ambos recebem assistência técnica e financeira do FNDE, ou então para aquisição de mobiliário e equipamentos adequados ao funcionamento da rede física escolar da educação infantil (cadeiras, berços, geladeira, mesas etc.).

Sendo assim, o município proponente pode optar entre a construção de escolas de educação infantil ou então a ampliação de estruturas do ProInfância já existentes. Quando optado pela construção o mesmo deve se enquadrar em um dos projetos-padrão, nomeados de: Tipo B, Tipo C, Tipo 1 e Tipo 2, fornecidos pelo próprio FNDE, que se diferenciam entre si quanto a capacidade do número de crianças atendidas (Tabela 1) e a metragem do terreno predefinidos pela autarquia, em consonância com as diretrizes da Secretaria de Educação Básica do MEC.

Tabela 1. Capacidade de atendimento do ProInfância

\begin{tabular}{|c|c|c|c|}
\hline $\begin{array}{c}\text { Categoria } \\
\text { CONSTRUÇÃO }\end{array}$ & $\begin{array}{c}\text { Capacidade de } \\
\text { atendimento }\end{array}$ & $\begin{array}{c}\text { Categoria } \\
\text { AMPLIAÇÃO }\end{array}$ & $\begin{array}{c}\text { Capacidade de } \\
\text { atendimento }\end{array}$ \\
\hline Tipo A & $\begin{array}{c}\text { Não há limite de } \\
\text { atendimento }\end{array}$ & \multirow[t]{2}{*}{ Tipo B } & \multirow[t]{2}{*}{96 crianças } \\
\hline Tipo B & 224 crianças & & \\
\hline Tipo C & 120 crianças & \multirow{3}{*}{ Tipo C } & \multirow{3}{*}{24 crianças } \\
\hline Tipo 1 & 376 crianças & & \\
\hline Tipo 2 & 188 crianças & & \\
\hline
\end{tabular}

Fonte: Adaptado do FNDE (2020).

Somente o Tipo A possibilita que o município apresente projeto próprio, porém seguindo as orientações e os parâmetros técnicos construtivos do FNDE, também avaliado pelo mesmo (FNDE 2007).

No entanto, independente do município proponente optar pela construção ou ampliação deve necessariamente atender critérios técnicos estabelecidos pelo Programa, tais como: a) apresentar demanda mínima conforme o projeto escolhido, de acordo os dados do Censo Escolar, observância dos Parâmetros Básicos de Infraestrutura para Instituições de Educação Infantil; b) seguir o projeto arquitetônico disponibilizado pelo FNDE; c) apresentar e ser aprovado um Plano de Ações Articuladas (PAR), no qual a análise fica a cargo de uma equipe técnica de Programas e Projetos Educacionais - DIRPE/FNDE; e, por fim, d) em caso de cons trução apresentar documentos que comprovem a propriedade do terreno por parte da proponente (BRASIL, 2007).

O ProInfância disponibiliza três manuais de orientação técnica para a execução do programa, entre eles: a) Seleção de terreno para edificações escolares e implantação de obras; b) Mobiliário e Equipamento Escolar: Educação Infantil e Elaboração de Projetos e Edificações Escolares: Educação Infantil. O primeiro 
manual tem como finalidade orientar o município proponente quanto a seleção do espaço a ser utilizado para construção das edificações dentro das escalas: global, local e do próprio terreno.

Quanto aos requisitos aplicáveis em escala global, devesse observar o “[...] nível de inserção urbana, onde deve ser avaliado o planejamento urbano municipal, as diretrizes e legislações urbanísticas considerando a (...) análise do entorno imediato (vizinhança)” (FNDE, 2017, p. 9). Em seguida, o planejamento territorial em escala local, o qual aborda os parâmetros físicos do terreno, isto é, “[...] quanto à dominialidade, ca racterísticas físicas (declividade, dimensionamento e solo) e condicionantes ambientais” (Ibidem); e, por último, os parâmetros de implantação no terreno em relação a “[...] critérios e procedimentos para a implantação da edificação (...) relativo ao bom desempenho da edificação” (FNDE, 2017, p. 10).

Quanto do manual sobre Mobiliário e Equipamento Escolar: Educação Infantil, ao considerar que os Centros de Educação Infantil são espaços em que as crianças passam boa parte de seu dia e lá vivenciam inúmeras experiências, este visa orientar quanto aos critérios de escolha buscando “[...] assegurar o padrão de qualidade adequado para o mobiliário e equipamento que compõem as escolas de ensino infantil” (FNDE, 2017, p. 09), haja vista que “[...] planejar esse ambiente para torná-lo educativo depende da qualidade das relações com o mundo material (objetos e mobiliário) e imaterial (concepções)” (Ibidem).

O manual para Elaboração de Projetos e Edificações Escolares: Educação Infantil, busca nortear quanto aos “[...] critérios, procedimentos e diretrizes fundamentais para elaboração dos projetos básicos de arqui tetura para essas edificações” (FNDE, 2017, p. 12), dando ênfase no âmbito da segurança, habitabilidade e da sustentabilidade.

Quanto à segurança intenta assegurar o desempenho estrutural de prevenção a incêndio e o uso operacional, já habitabilidade visa o cuidado quanto ao desempenho térmico, acústico, higiene/saúde, acessibilidade, conforto tátil e antropo-dinâmico da edificação a ser assegurado ao usuário. Por fim, a sustentabilidade da edificação que se baseia quanto à durabilidade, manutenibilidade e adequação ambiental, ou seja, a durabilidade compreendida entre o período de "[...] início de operação ou uso de um produto e o momento em que o seu desempenho deixa de atender às exigências preestabelecidas do usuário” (FNDE, 2017, p. 40), denominado de vida útil, e a manutenibilidade “[...] grau de facilidade de um sistema, elemento ou componente de ser mantido ou recolocado no estado no qual possa executar suas funções requeridas” (Ibidem).

Por fim, a adequação ambiental do empreendimento e sua infraestrutura “[...] devem ser projetados, construídos e mantidos de forma a minimizar as alterações no ambiente” (FNDE, 2017, p. 41), entre eles o “[...] arruamento, drenagem, rede de água, gás, esgoto, telefonia e energia” (Ibidem). Observa-se dentro des sa proposta, mesmo sem muita ênfase, uma preocupação quanto a sustentabilidade ambiental do espaço arquitetônico, no entanto não aborda de forma específica como esse espaço projetado poderia contribuir para o desenvolvimento de práticas educativas sustentáveis.

\section{Práticas Educativas Sustentáveis Na EdUCAÇão INFANTIL}

As últimas décadas têm se discutido muito sobre a relação do ser humano e o planeta Terra, assim como tem gerado alguns questionamentos quanto suas atitudes e a emergência de reavaliar sua relação de descuido com o meio ambiente. Os espaços formais de ensino acabam se transformando em uma das alternativas para trabalhar e abordar a reflexão sobre a ação do ser humano sob os recursos naturais, pautado na reflexão de valores e atitudes que se utilizam da “[...] prática pedagógica em ações que visam humanizar e concretizar a melhoria da qualidade e vida do planeta” (HAMMES; RACHWAL, 2012, p. 41). 
Nessa lógica, a Educação Infantil tem se deparado com a necessidade de abordar conhecimentos complexos pautados em valores que possam contribuir para orientar a criança quanto sua visão de futuro, o qual não seja predominantemente "[...] marcado pelo imediatismo, consumismo, efemeridade de valores, superficialidade e pasteurização das informações” tal qual se vivência no cotidiano social (SETUBAL, 2015, p. 22).

Dentro dessa visão se questiona: como construir uma educação de qualidade para todos e com valores que possam ser duradouros para acompanhar o aluno em sua vida adulta, sem que com isso se perca a ludicidade tão necessária para o desenvolvimento da infância? Na intenção de encontrar respostas uma das possibilidades para os Centros de Educação Infantil é buscar desenvolver uma proposta pedagógica que vise o desenvolvimento de práticas educativas sustentáveis, porém, antes de tudo precisa estar preparada para mudanças revolucionárias e significativas de seus princípios, percepção e valores, assim como destaca Ingold (2000):

Ao habitar o mundo, nós não apenas agimos sobre ele ou realizamos coisas para ele, mas, mais do que isso, nós nos movemos junto com ele. Nossas ações não transformam o mundo, elas são parte do mundo transformando a si mesmo (apud SETUBAL, 2015, p. 22).

Intenta com essa discussão trazer um pequeno ensaio que possibilite a reflexão sobre a teoria e a prática dentro da proposta de trabalho com o público infantil, na perspectiva de lhe aproximar da vivência com a na tureza ao possibilitar que construa seus próprios conceitos sobre: vida (começo/meio/fim), dependência entre os elementos naturais (terra/água/ar) e pertencimento ao meio ambiente, pois a “[...] teoria deslocada da rea lidade é uma abstração que tende a reproduzir como universal os valores (...) e prática sem reflexão teórica é ação ativa não consciente” (LOUREIRO, 2012, p. 144), que age sem compreensão.

Sendo assim, pensar como é possível ensinar essas crianças com tão pouco conhecimento de mundo o sentido da vida e a importância dos recursos naturais, que compõem esse imenso organismo vivo chamado planeta Terra, se torna um dos principais desafios para uma prática sustentável significativa. Trazer uma práxis educativa a partir de uma das atividades mais importantes e significativas para a criança, que é o brincar, contribuiu para sua formação e traz "[...] à liberdade e às escolhas conscientes, feitas pela interação dialógica que estabelecemos como o outro, a sociedade e o mundo” (LOUREIRO, 2012, p. 144).

Ações essas importantes quando se pensa em práticas educativas sustentáveis, pois trabalha com conceitos chaves como “[...] conhecer, agir e se perceber no ambiente” (Ibidem). Logo, tendo em vista que a infância é considerada uma das etapas do desenvolvimento humano mais sensível às influências do meio social e físico, durante essa fase as aprendizagens básicas da criança estão mais propensas, onde tudo que se vive, sente, vê, experimenta marca mais profundamente sua personalidade do que em qualquer outra idade, se torna significativo dar especial atenção às possibilidades de interação com a natureza proporcionada nesse momento da vida (DIDONET, 2018).

Outro aspecto bem característico dessa fase da vida humana e o brincar, desprovida de segundas intenções é a forma que a criança se apropria para conhecer o mundo ao seu redor e compreender as regras de convívio social de forma prazerosa. Dentro dos espaços educacionais o lugar que mais acontece essa interação são os pátios escolares, os quais podem ser vistos como lugares de socialização, de troca, de convívio; bem como, de experimentação e exploração, sendo redutos da circulação de saberes, hábitos, costumes, rituais e brincadeiras que fazem parte da cultura da infância e que têm sido transmitidas entre seus pares por gerações (BARROS, 2018).

Brincar livremente possibilita o desenvolvimento da criatividade, da iniciativa, da autoconfiança, da capacidade de escolhas, de tomar decisões e resolver problemas, o que por sua vez contribui para o desenvolvi- 
mento integral da criança, aspectos esses que quando aliados com a possibilidade do convívio com elementos da natureza podem trazer "[...] benefícios mais ligados aos campos da ética e da sensibilidade, como encantamento, empatia, humildade e senso de pertencimento” (BARROS, 2018, p.17), que o ambiente natural proporciona.

Nesta vertente, as Diretrizes Curriculares Nacionais para a Educação Infantil - DCNEI (2009) corrobo ram ao destacar que as práticas pedagógicas a serem desenvolvidas devem ter como eixos norteadores as interações e a brincadeira, garantindo assim, dentre vários aspetos que:

Incentivem a curiosidade, a exploração, o encantamento, o questionamento, a indagação e o conhecimento das crianças em relação ao mundo físico e social, ao tempo e à natureza; (...) promovam a interação, o cuidado, a preservação e o conhecimento da biodiversidade e da sustentabilidade da vida na Terra, assim como o não desperdício dos recursos naturais (BRASIL, 2009, p. 25-26, grifos nossos).

Com base nesses argumentos essa proposta investigativa visa analisar as possibilidades de desenvolvimento de práticas educativas sustentáveis nos Centros Municipais de Educação Infantil construídos pelo ProInfância que tornam possível a integração dessas experiências. Assim, optou-se em dialogar com os espaços que possibilitam maior movimento e interação da criança com seus meios, ou seja, os espaços abertos e livres que possibilitam a exploração, investigação e a construção do conhecimento.

Nessa perspectiva, primeiramente, convêm conhecer quais são os espaços destinados ao brincar, explorar e conhecer dentro da proposta do ProInfância. A descrição desses espaços consta no manual de Elaboração de Projetos e Edificações Escolares: Educação Infantil que apresentam três ambientes externos: o solário, pátio coberto e o pátio descoberto com parquinho.

O solário é designado a bebês de 3 a 11 meses e “[...] são os espaços reservados destinados ao banho de sol das crianças” (FNDE, 2017, p. 161), devendo ser uma extensão dos “[...] berçários e as salas de atividades, sendo de uso exclusivo do grupo desta faixa etária (...) e ainda ser implantado buscando a orientação so lar adequada” (Ibidem).

O pátio coberto é “[...] destinado à recreação das crianças e à realização de atividades coletivas em espa ço coberto e protegido do sol e chuva” (FNDE, 2017, p. 163), como também para a “[...] realização de atividades diversas - lazer, festas, eventos, de utilização dinâmica e flexível, atendendo quando possível também aos pais e/ou comunidade externa" (Ibidem). Este espaço é destinado para as crianças de 1 ano a 5 anos e 11 meses.

Quanto ao pátio descoberto com parquinho’ deve ser “[...] destinado à recreação e à realização de atividades coletivas” (FNDE, 2017, p. 166), sendo recomendado que este local permita permeabilidade visual e física apresentando espaços "[...] diversificados, sombreados e descobertos, áreas permeáveis, pisos variados como grama e areia, bancos e brinquedos como escorregador, balanço, túneis, casa de boneca, etc. (Ibidem)”, assim também, “[...] quando possível, prever área para jardim, pomar e horta, estimulando o envolvimento da comunidade escolar” (Ibidem).

Sendo assim, como mecanismo de discussão das práticas educativas sustentáveis que podem ser realiza das a partir da infraestrutura proposta pelo ProInfância optou-se pelo trabalho com imagem para melhor exemplificação do assunto tratado. Para tanto, no transcorrer das reflexões serão apresentadas imagem de Centros Municipais de Educação Infantil construídos por meio do programa atendendo a categoria construção do Tipo B (Tabela 1) e imagens de outros Centros Municipais, os quais não seguem as regras do progra- 
ma que aqui serão denominadas de Centro Municipais alternativos, pois são projetados conforme interesse da municipalidade.

A primeira imagem a ser analisada são dos solários construídos pelo ProInfância (Figura 1). Conforme se observa tanto a imagem $A$ como a $B$ seguem normatizações gerais quanto altura, comprimento e arquitetura a ser seguido pelo programa. Porém, o que chama atenção do projeto é o fato de não priorizar a valoriza ção do conhecer e explorar, aspectos tão significantes para a Primeira Infância, pois, não traz recomendações que poderiam normatizar o uso de material que possibilita observar e até mesmo ter contato físico com os elementos naturais que possam estar envolto desse espaço.

Figura 1. Solário
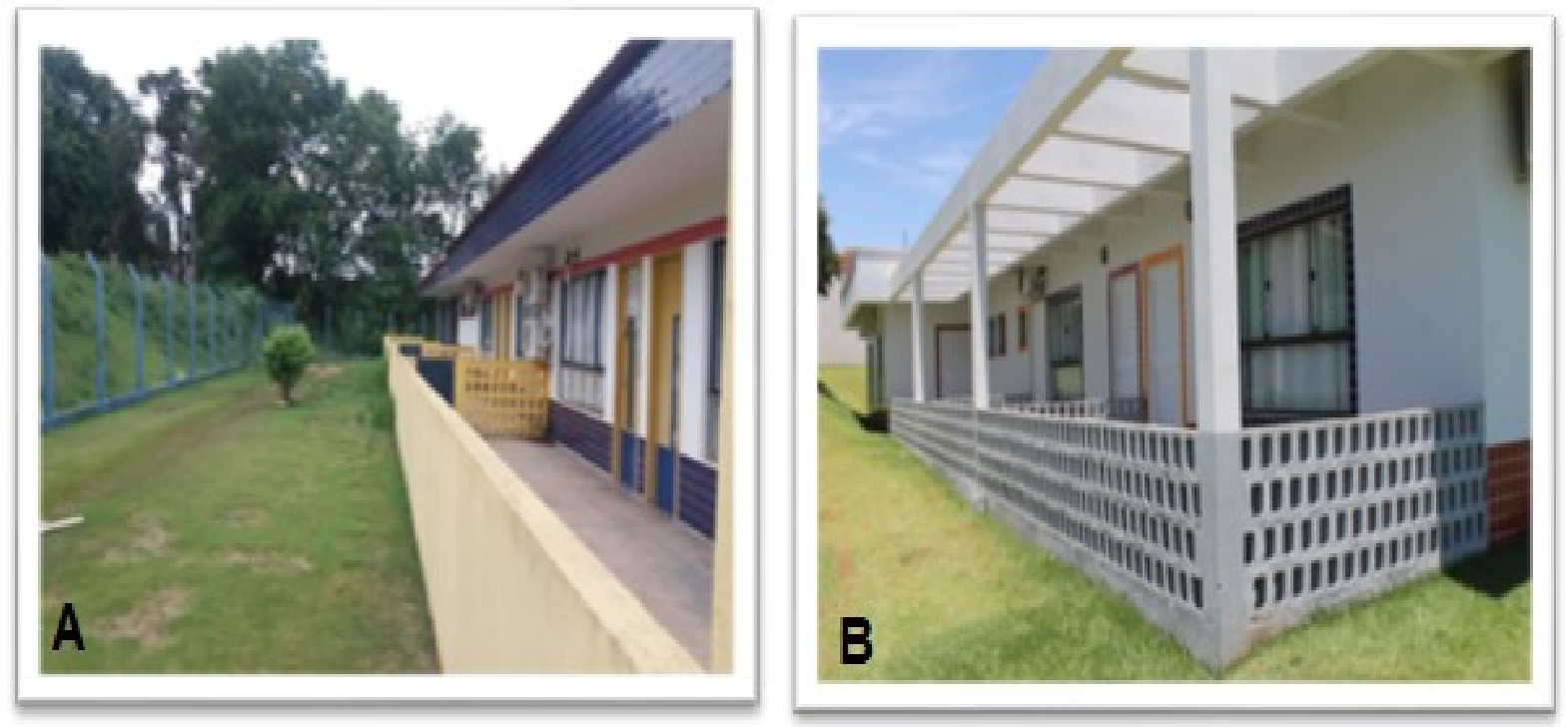

Fonte: Arquivo próprio (2019).

No entanto, se pode observar que a contribuição quanto às possibilidades de utilizar esse espaço para o desenvolvimento de práticas educativas sustentáveis dependerá da visão do gestor durante a execução do projeto, pois o que diferencia os dois salários são as possibilidades presentes no muro que cerca o mesmo, a qual a imagem $A$ demonstra total inviabilidade da criança olhar para além do concreto, enquanto a imagem $B$, além de trazer os pequenos furos que possibilita a criança olhar, traz também a proposta de alongamento do telhado com uma cobertura transparente que possibilita utilizar esse espaço em diferentes horas do dia, devido a chance reduzida de aquecimento do chão.

Isto o que inviabiliza a presença dos pequenos como também traz a claridade proporcionada pela transparência que dentro de uma proposta sustentável diminui a necessidade do uso de luz artificial. Um aspecto que poderia ser explorado nesse espaço seria a abertura do acesso por meio de pequenos portões, os quais permitiriam a criança ir de encontro para explorar o ambiente.

A segunda imagem analisada é a caixa de área que vem também como proposta do ProInfância (Figura 2), ela é uma excelente ferramenta para que a criança construa e desconstrua possibilidade de brincar, muito mais do que um elemento natural ela se torna um campo de experiência capaz de proporcionar o prazer de criar, experimentar no exercício de sua imaginação e habilidade motoras, considerando que as: 
[...] experiências multissensoriais na natureza ajudam a construir as habilidades cognitivas necessárias para o desenvolvimento intelectual continuo e estimulam a imaginação ao oferecer a criança o espaço e os materiais para (...) a arquitetura e os artefatos (LOUV, 2016, p. 108).

De tal modo, ao avaliarmos os dois espaços, tanto o construído pelo ProInfância quanto do Centro Municipal alternativo (Figura B), o planejamento e cuidado em preparar a caixa de areia colocando dentro de um ambiente arborizado que permite a criança brincar em qualquer hora do dia como também estar em contato direto com esse ambiente. Contribuiu ainda para a construção de conceitos relacionados as estações do ano que alteram as formas das árvores, a presença de seres vivos que podem ocupar esse lugar, por exemplo, pássaros, possibilitando assim trazer o sentimento de pertencimento desconstruindo a visão antropocêntrica, a qual dissocia o ser humano da natureza.

A Figura 2 apresenta além da opção da caixa de areia também a de pedra, no entanto, sua localização se apresenta desfavorável para o uso infantil, pois se observa desprovido de sombra e a tentativa de proporcioná-la, por meio do plantio de árvores, se concentra apenas em uma parte do espaço quando essa poderia contornar as caixas. Outro aspecto que chama atenção é a falta de artefatos, como obstáculos planejados com aparatos naturais, como troncos e pedras maiores que se possibilita atividades lúdicas, não necessitando as sim que se traga artefatos industrializadas para esse espaço.

Figura 2. Caixa de areia e pedra
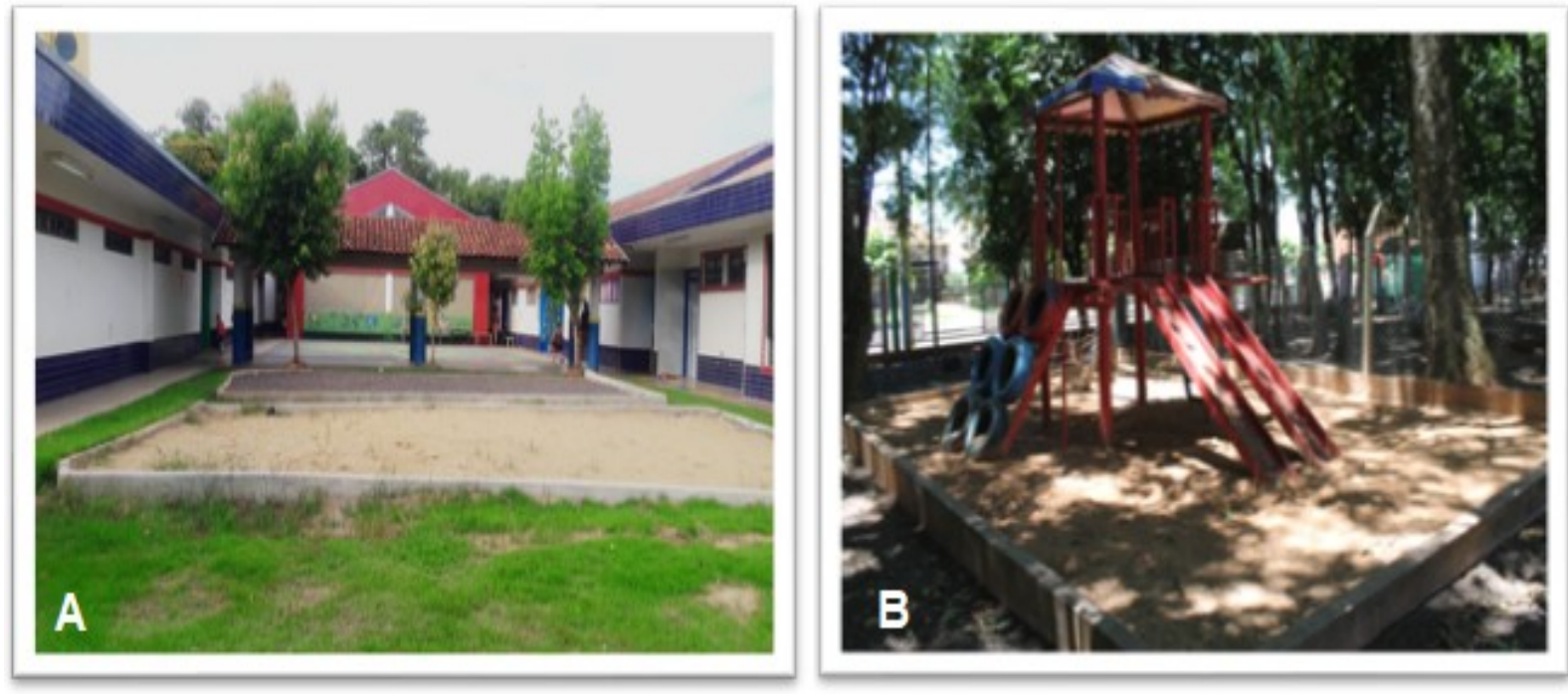

Fonte: Arquivo próprio (2019).

O espaço descoberto e/ou externo dos Centros de Educação Infantil pode se tornar lugares de práticas sustentáveis quando este possibilita que a criança usufrua dele em qualquer hora e momento do dia, e que, além disso, possa ofertar artefatos soltos para a construção de seu brincar: por exemplo, “[...] árvores, arbus tos, flores e capim, um lago e os seres vivos que vivem nele; areia (...) lugares para entrar, sentar e se escon der; estruturas que ofereçam privacidade e paisagens” (LOUV, 2016, p. 108).

A sustentabilidade se encontra, quando a redução do consumo e o repensar em novas alternativas de criar o próprio brinquedo e a brincadeira, de acordo com o que a própria natureza oferta, se torna além de uma ferramenta interessante para o desenvolvimento motor e cognitivo da criança a possibilita de despertar outros 
valores que não necessariamente esteja relacionado a cultura do consumismo infantil. Igualmente, permite trabalhar desde a mais tenra idade aspectos relacionados ao econômico, cultural, social e ambiental.

Econômico no sentido do supérfluo e descartável atribuído aos brinquedos na atualidade, o social quanto a equidade de acesso. As possibilidades de brincar são justas e igualitárias para todos, o cultural desmistifica a construção realizada pela mídia e o mundo capitalista regido pelo ter muito mais do que o ser, o qual não mede esforços com relação à exploração da natureza (BOFF, 2001).

E, por fim, o ambiental que se trabalhado todos os aspectos contribuiu para a formação de futuros cidadãos mais engajados e comprometidos com os valores e cuidado atribuído ao meio ambiente. Nesse viés, a Figura 3 aborda a possibilidade de permeabilidade física e visual, conforme sugerido dentro do ProInfância.

Figura 3. Espaço aberto / parquinho
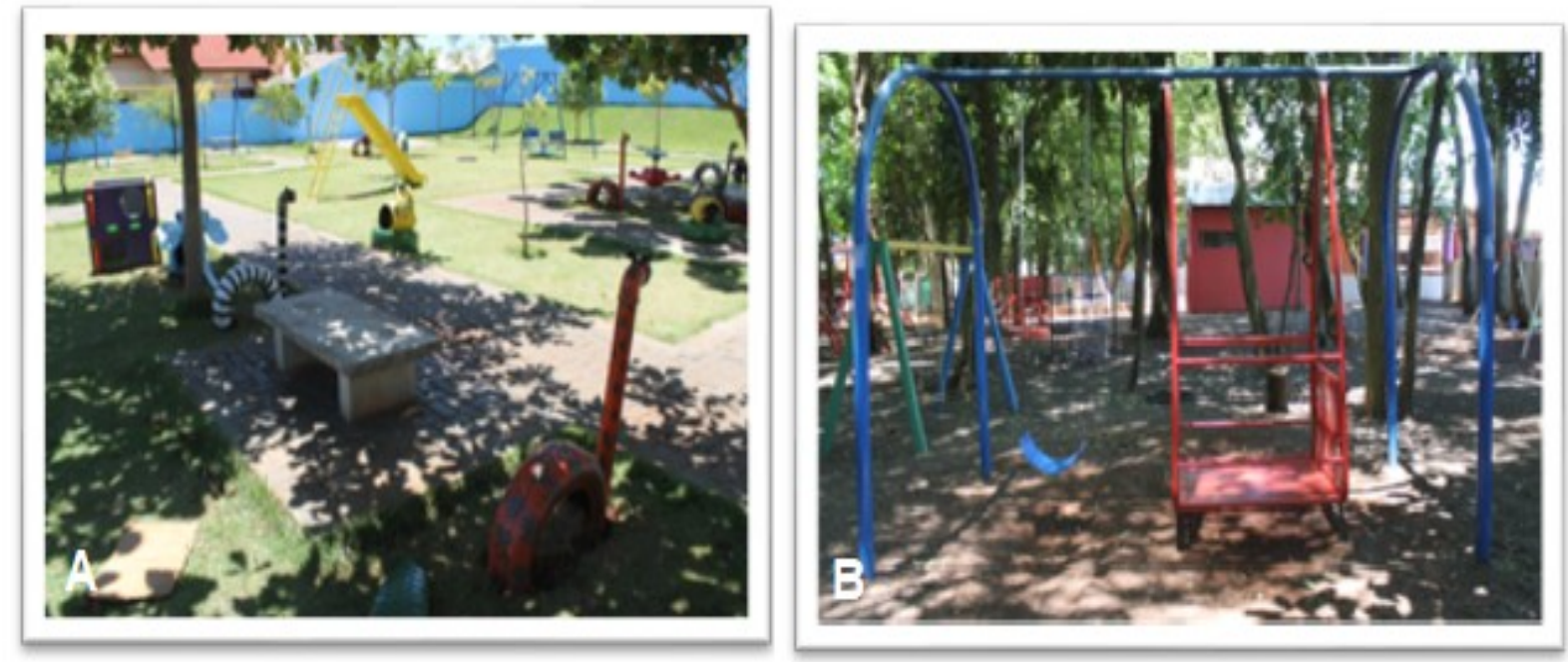

Fonte: Arquivo próprio (2019).

A permeabilidade nesse contexto é trabalhada dentro de conceitos específicos da arquitetura, no qual estuda no momento da construção de um projeto arquitetônico a configuração de determinado espaço aberto e as barreiras que podem influenciar, tanto o movimento quanto da visibilidade nos padrões de sua utilização (SABOYA et al., 2014).

A imagem A apresenta um amplo espaço com um parquinho construído em um dos Centros Municipais de Educação Infantil do ProInfância, observa-se que ele apresenta apenas uma vegetação rasteira, dentro da proposta de permeabilidade visual e física, pois, permite de uma certa distância observar as crianças diante de qualquer situação de risco, assim como não apresenta nenhum obstáculo natural. Já a imagem $B$ se apresenta totalmente oposta a primeira, seu chão e coberto de terra e pedras com muitas árvores distribuídas no espaço.

Apesar da quantidade de árvores traz também uma 'permeabilidade visual', no entanto a física com a quantidade de árvores contribui para ressignificar outras brincadeiras, como pega - pega e esconde-esconde, as quais se utilizam do próprio corpo para serem realizadas.

Um aspecto que pode ser destacado nas duas imagens é a falta de outros elementos naturais, que não seja a árvore e a grama, como por exemplo, pequenos arbustos, flores, trepadeiras, entre outros, que podem ser considerados pequenos mundinhos, onde se encontra as mais diversas formas de vida (borboleta, joanina, 
grilo, mariposa, caracol, minhoca, etc.) que compõem a biodiversidade de nosso planeta e que despertam o interesse e a curiosidade das crianças podendo facilmente se tornar uma aula de ciências e educação ambiental a céu aberto.

Diante da proposta de se pensar no desenvolvimento de práticas educativas sustentáveis, relacionadas aos espaços destinados ao brincar e as maneiras de tornar esse espaço mais naturalizado é preciso cuidar com propostas que visam o reaproveitamento de materiais como os pneus (Figura $3 \mathrm{~A}$ ), apesar de aparentemente se mostrar como uma alternativa para incrementar os espaços infantis e trazer a percepção de uma junção possível (natureza/resíduo sólido), no entanto, não se discute a contaminação causada por esses elementos reforçando para a criança, em fase de construção de conceitos, a naturalidade e normalidade dessa interação.

\section{CONSIDERAIS FINAIS}

A princípio, parece um tanto quanto simplista, pensar que uma prática educativa que busca substituir o brincar com elementos industrializados por artefatos soltos, oriundos da natureza, possa contribuir para a sustentabilidade. Porém, se observa que quando desenvolvida de forma planejada tornando esses momentos de brincar ao ar livre prazeroso e cheio de descobertas se tem grande chance de ser reproduzido pelas pró prias crianças em seus espaços familiares e comunitário.

E, ao descobrirem os prazeres incutidos no desenvolvimento de sua própria criatividade, apresenta grande chance de optarem por brincar livremente desprendidos de artefatos industrializados. O espaço externo de um Centro Municipal de Educação Infantil pode ser muito mais do que um simples lugar de correr e brincar, ele pode se tornar um laboratório de vivência e conhecimento do mundo natural e proporcionar a criança, brincar e interagir com os elementos da natureza, acompanhar seu ciclo de vida, observar os minúsculos insetos presentes em seu jardim, aprender a cuidar e se familiarizar com a dependência entres todas as formas de vida do planeta Terra.

O professor enquanto mediador dessa aprendizagem pode aproveitar os momentos de curiosidade avivados entre uma brincadeira e outra para trabalhar aspectos significativos como: ética, a sensibilidade, cuidado e o despertar do pertencimento da criança ao mundo natural. Isto posto conclui-se que diante da dimensão territorial de alcance do ProInfância ele poderia ser melhor aproveitando quanto a sua normatização de espaços mais sustentáveis, principalmente os espaços destinados ao brincar, que conforme estudado, representa uma ação importante e significativa para o desenvolvimento infantil.

Outro aspecto que se evidenciou na pesquisa diz respeito a organização e intencionalidade de que faz a gestão desses espaços depois de pronto, seja dos Centros Municipais de Educação Infantil construídos pelo ProInfância, seja os Centros Municipais alternativos, de torná-los mais naturalizadas e repletos de significados, para que assim a criança possa brincar e ao mesmo tempo desenvolver os mais diferentes aspectos relacionados a ética e ao cuidado.

\section{REFERÊNCIAS}

ANDRADE, Lucimary Bernabé Pedrosa. Educação infantil: discurso, legislação e práticas institucionais. São Paulo: Editora UNESP; São Paulo: Cultura Acadêmica, 2010.

BARROS, Maria Isabel Amando de (Org.). Desemparedamento da infância: A escola como lugar de encontro com a natureza. 2. ed. Rio de Janeiro: Alana, 2018. 
BOFF, Leonardo. Saber Cuidar: Ética do humano - compaixão pela terra. Rio de Janeiro: Editora Vozes, 7ª Ed., 2001. BRASIL. Constituição Federal, 1988. Brasília.

. Decreto $\mathbf{n}^{\mathbf{0}}$ 6.094, de 24 de abril de 2007. Dispõe sobre a implementação do Plano de Metas Compromisso Todos pela Educação, pela União Federal, em regime de colaboração com Municípios, Distrito Federal e Estados, e a participação das famílias e da comunidade, mediante programas e ações de assistência técnica e financeira, visando a mobilização social pela melhoria da qualidade da educação básica. Brasília, 2007.

. Lei nº 9394/1996, de 20 de dezembro de 1996. Lei de Diretrizes e Bases da Educação Nacional - LDB.

. Resolução no 5, de 17 de dezembro de 2009 Fixa as Diretrizes Curriculares Nacionais para a Educação Infan til. Brasília, 2009.

Resolução no 6, de 24 de abril de 2007. Estabelece as orientações e diretrizes para execução e assistência financeira suplementar ao Programa Nacional de Reestruturação e Aquisição de Equipamentos para a Rede Escolar Pública de Educação Infantil - PROINFÂNCIA. Brasília, 2007.

DIDONET, Vital (Org.). Marco legal da Primeira Infância: A lei mais avançada do mundo para atender e zelar pelos direitos da criança pequena. 2018. Disponível em: <https://www.passeidireto.com/arquivo/56115201/introducao-aomarco-legal-da-prmeira-infancia-texto-para-dep-leandre $\geq$. Acesso em: 19 jan. 2020.

DROUET, Ruth Caribé da Rocha. Fundamentos da Educação Pré-escolar. 2. ed. São Paulo: Editora Ática S.A, 1995.

FALCIANO, Bruno Tovar; NUNES, Maria Fernanda Rezende; SANTOS, Edson Cordeiro dos. Dez anos do ProInfância: efeitos de uma política pública de indução. Estudos em Avaliação Educacional, [s.l.], v. 30, n. 73, p.254-278, 31 maio 2019. Fundação Carlos Chagas.

FNDE. Elaboração de Projetos e Edificações Escolares: Educação Infantil. Manual de Orientações Técnicas; v.1. Brasília - DF: FNDE, 2017.

. Mobiliário e Equipamento Escolar: Educação Infantil. Manual de Orientações Técnicas; v.1. Brasília - DF: FNDE, 2017.

Seleção de terrenos para edificações escolares e implantação de obras. Manual de Orientações Técnicas; v.1. Brasília - DF: FNDE, 2017.

.. Projetos Arquitetônicos para construção. Disponível em: <https://www.fnde.gov.br/index.php/programas/ proinfancia/eixos-de-atuacao/projetos-arquitetonicos-para-construcao>. Acesso em: 15 jan. 2020.

Sobre o ProInfância. 2007. Disponível em: <https://www.fnde.gov.br/index.php/programas/proinfancia/sobreo-plano-ou-programa/sobre-o-proinfancia>. Acesso em: 15 jan. 2020.

HADDAD, Fernando. O Plano de Desenvolvimento da Educação: razões, princípios e programas. Brasília: Ministério da Educação; Instituto de Estudos e Pesquisas Educacionais Anísio Teixeira, 2008.

HAMMES, Avaléria Sucena; RACHWAL, Marcos Fernando Gluck. Meio ambiente e escola. 7. ed. Brasília: Embrapa, 2012.

KUHLMANN Jr., Moysés. Infância e Educação Infantil: uma abordagem histórica. 6. ed. Porto Alegre: Mediação, 2011.

LOUREIRO, Carlos Frederico B. Trajetória e Fundamentos da Educação Ambiental. 4. ed. São Paulo: Cortez, 2012.

LOUV, Richard. A última criança na natureza: resgatando nossas crianças do transtorno do déficit de natureza. (tradução Alyne Azuma, Cláudia Belhassof). 1 ed. - São Paulo: Aquariana, 2016. 
MENDES, Sarah de Lima. Tecendo a história das instituições do Brasil infantil. Saberes, Natal - RN, v. 1, n. 11, Fev. 2015.

ROMAN, Eurilda Dias; STEYER, Vivian Edite (Org.). A criança de 0 a 6 anos e a Educação Infantil: um retrato multifacetado. Canoas: Ulbra, 2001.

SABOYA, Renato T. de et al. Padrões de visibilidade, permeabilidade e apropriação em espaços públicos abertos: um estudo sintático. Revista Vitruvius, São Paulo, v. 1, n. 164, Jan. 2014. Disponível em: <https://www.vitruvius.com.br/ revistas/read/arquitextos/14.164/5015>. Acesso em: 25 jan. 2020.

SETUBAL, Maria Alice. Educação e sustentabilidade: princípios e valores para a formação de educadores. São Paulo: Peirópolis, 2015. 